\title{
SURVEY EPIDEMIOLOGI: HUBUNGAN ANTARA PERILAKU KESEHATAN GIGI MULUT DENGAN INDEKS DMF-T LANSIA USIA 45-65 TAHUN DI KECAMATAN KRONJO, KABUPATEN TANGGERANG
}

Lisa Prihastari ${ }^{*}$, Puteri Mentari Siregar ${ }^{* *}$, Rizka Indirasari Nur ${ }^{* *}$, Sherly Mentari ${ }^{* *}, Z_{\text {Zllia Taftyanti }}^{* *}$

\section{\begin{tabular}{|c|}
\hline Keywords: \\
Epidemiology Survey; \\
Elderly; Geriatry; Oral \\
Health Behavior; DMFT
\end{tabular}}

\section{ABSTRACT}

Background: The number of elderly population growing fastly in Indonesia along with the increase of life expectancy. Oral health of elderly people greatly affect the quality of life. Oral health in the elderly is reflected in the number of missing teeth (tooth loss), dental caries and periodontal disease.

Objective: To know the relationship of Elderly oral health behavior with DMFT index

Methods: Cross-sectional survey with WHO's method was done by multistage random sampling at 124 age 45-64 years old in Kronjo sub-district, Tangerang. The data was collected by DMFT examination and the standard questionnaire of WHO survey. Calibration test for four examiners with Kappa value was 0.75

Results: The mean score of DMFT was 15.5 is included in the very high category. There was statistically significant association between elderly selfassessment and toothpaste use with DMFT index $(p=0,016 ; p=0,009)$. There was no significant association between sweet consuming and dental pain with mean DMFT index $(p=0.216 ; p=0.324)$

Conclusion: Oral Health Behavior of the Elderly in Kronjo sub-district is still poor with a very high score of DMFT that will require immediate attention from the government.

\section{PENDAHULUAN}

Salah satu indikator adanya keberhasilan dalam pembangunan negara adalah semakin meningkatnya usia harapan hidup penduduknya. Meningkatnya usia harapan hidup penduduk ini akan memberikan dampak pada kenaikan jumlah penduduk lanjut usia (lansia) setiap tahun. Jumlah lansia di seluruh dunia diperkirakan sebanyak 500 juta dengan usia rata-rata 60 tahun dan tahun 2025 akan mencapai 1,2 milyar. Di seluruh dunia penduduk lansia tumbuh dengan sangat cepat bahkan tercepat dibanding kelompok usia lainnya. ${ }^{1}$ Badan kesehatan dunia WHO menyatakan bahwa penduduk lansia di Indonesia pada tahun 2020 mendatang sudah mencapai angka $11,34 \%$ atau tercatat 28,8 juta yang mengalami peningkatan dari jumlah lansia pada tahun 2005 yaitu $8,48 \%$, merupakan jumlah penduduk lansia terbesar di dunia. ${ }^{1,2}$

Bersamaan dengan bertambahnya usia terjadi penurunan fungsi organ tubuh dan berbagai perubahan fisik. Penurunan ini terjadi pada semua tingkat seluler, organ, dan sistem. Perubahan pada rongga mulut akan menyebabkan rentan terjadi karies dan penyakit periodontal yang merupakan penyebab hilangnya gigi pada lansia. Karies terjadi karena demineralisasi jaringan permukaan gigi oleh asam organis yang berasal dari makanan yang mengandung gula. Karies gigi bersifat kronis dan dalam 
perkembangannya membutuhkan waktu yang lama. Indikator untuk menilai karies gigi yang utama digunakan adalah indeks DMF-T yang merupakan penjumlahan indeks $\mathrm{D}+\mathrm{M}+\mathrm{F}$, yang menunjukkan banyaknya kerusakan gigi yang pernah dialami seseorang karena karies gigi baik berupa D/Decay (gigi berlubang/karies), $\mathrm{M} /$ missing (gigi hilang) serta F/filling (gigi ditumpat). ${ }^{3,4}$

Di Indonesia, berdasarkan hasil survey RISKESDAS tahun 2013, terdapat 31,9\% penduduk Indonesia memiliki masalah gigi dan mulut dengan proporsi usia 35-44 tahun serta sebanyak $28,3 \%$ pada proporsi usia 55 64 tahun, indeks karies gigi (DMF-T) nasional sebesar 4,6 yang dapat diartikan kerusakan gigi penduduk Indonesia adalah 460 gigi per 100 orang. Di propinsi Banten terdapat 23, $7 \%$ penduduk yang mengalami masalah gigi dan mulut, indeks DMF-T di Banten sebesar 3,7. Sedangkan indeks DMF-T di Banten pada proporsi usia 45-54 tahun sebesar 7, 02 serta sebesar 12, 3 pada proporsi usia 5564 tahun. Berkaitan dengan itu terdapat pula data RISKESDAS 2013 di propinsi Banten yaitu indeks karies aktif pada usia 45-54 tahun sebesar $62,2 \%$ serta sebesar $69,4 \%$ pada proporsi usia 55-64 tahun.5

Berdasarkan gambaran di atas peneliti ingin melakukan penelitian mengenai hubungan antara perilaku memelihara kesehatan gigi dengan terjadinya karies gigi pada masyarakat usia pra-lansia dan lansia yaitu dalam rentang usia 45-65 tahun.

\section{METODE PENELITIAN}

\section{Desain dan sampel penelitian}

Penelitian observasional dilakukan dengan desain survey cross-sectional pada Lansia usia 45-65 tahun sebanyak 124 orang di
Desa Pagedangan Ilir, Kecamatan Kronjo, Kabupaten Tangerang pada bulan Maret 2017. Pemilihan desa dilakukan dengan metode simple random sampling.

\section{Penilaian status karies}

Pemeriksaan dilakukan oleh empat orang pemeriksa yang telah di kalibrasi dengan hasil uji kappa 0, 75. Pemeriksaan dilakukan dengan menggunakan kaca mulut serta probe periodontal WHO selanjutnya dilakukan pengisian data odontogram untuk mengetahui status DMF-T.

\section{Kuesioner}

Data mengenai perilaku subyek penelitian di kumpulkan melalui kuesioner WHO yang telah di uji validitas dan reabilitasnya.

\section{Pengolahan dan analisis data}

Analisis data pada penelitian ini menggunakan SPSS dengan level signifikansi $5 \%$ (p-value <0.05). Frekuensi, rata-rata, standar deviasi (SD), dan persentase dihitung untuk analisis deskriptif. Uji Kolmogorovsmirnov (KS) digunakan untuk menentukan distribusi normal dari Nilai DMF-T, karena hasil data menunjukkan bahwa data tidak normal, maka selanjutnya digunakan uji non parametrik yaitu uji Mann Whitney dan Kruskal-wallis.

\section{HASIL PENELITIAN}

Jumlah subjek pada penelitian ini adalah 124 orang, dengan rata-rata usia subjek adalah 51, 99 tahun. Berdasarkan kelompok usia untuk 45-55 tahun sebanyak 91 orang dan 56-65tahun sebanyak 33 orang. Pada survey ini, rata-rata DMFT adalah $15.51 \pm 7.5$ dan prevalensi karies sebesar $95.16 \%$. Sedangkan hasil PTI (performance treatment index) yang 
Tabel 1. Nilai, komponen indeks DMF-T dan prevalensi karies Lansia berdasarkan usia status sosiodemografi

\begin{tabular}{lccc}
\hline & $\begin{array}{c}\text { Usia 45-55 } \\
(\mathbf{n}=\mathbf{9 1})\end{array}$ & $\begin{array}{c}\text { Usia 56-65 } \\
(\mathbf{n}=\mathbf{3 3})\end{array}$ & $\begin{array}{c}\text { Total } \\
(\mathbf{n}=\mathbf{1 2 4})\end{array}$ \\
Kriteria & & & \\
\hline D-T & $7.2 \pm 5.21$ & $6.82 \pm 4.15$ & $7.1 \pm 4.94$ \\
M-T & $6.78 \pm 6.2$ & $12.15 \pm 8.22$ & $8.21 \pm 7.17$ \\
F-T & $0.12 \pm 0.87$ & $0.42 \pm 1.80$ & $0.2 \pm 1.2$ \\
DRoot-T & $0.47 \pm 1.33$ & $1.70 \pm 2.7$ & $0.8 \pm 1.9$ \\
DMF-T & $14.10 \pm 6.94$ & $19.39 \pm 7.69$ & $15.51 \pm 7.5$ \\
D-T/DMF-T & $51.05 \%$ & $35.16 \%$ & $45.76 \%$ \\
M-T/DMF-T & $47.64 \%$ & $62.65 \%$ & $52.94 \%$ \\
F-T/DMF-T & $0.86 \%$ & $2.19 \%$ & $1.3 \%$ \\
PP Karies gigi & $94.5 \%$ & $97 \%$ & $95.16 \%$ \\
\hline
\end{tabular}

Tabel 2. Karakteristik Distribusi Sosiodemografi dan DMF-T Lansia

\begin{tabular}{lccc}
\hline \multicolumn{1}{c}{ Variabel } & N(\%) & \multicolumn{2}{c}{ DMF-T } \\
\cline { 3 - 4 } & & Mean \pm SD $)$ & $p^{\mathbf{a}}$ \\
\hline Usia & & & $0.001^{* *}$ \\
$45-55$ & $91(73.4 \%)$ & $14.10 \pm 6.94$ & \\
$56-65$ & $33(26.6 \%)$ & $19.39 \pm 7.69$ & \\
Jenis Kelamin & & & 0.05 \\
Laki-laki & $30(24.2 \%)$ & $13.13 \pm 6.4$ & \\
Perempuan & $94(75.8 \%)$ & $16.27 \pm 7.7$ & \\
Pendidikan Teralkhir & & & $0.014 *$ \\
SMA & & & \\
SMP & $3(2.4 \%)$ & $18.7 \pm 8.5$ & \\
SD & $7(5.6 \%)$ & $11.43 \pm 4.1$ & \\
Tidak Sekolah & $16(12.9 \%)$ & $11.06 \pm 4.1$ & \\
Jenis Pekerjaan & $98(79 \%)$ & $16.43 \pm 7.8$ & \\
Nelayan & & & 0.072 \\
Tbu RT & $21(16.9 \%)$ & $12.43 \pm 6.7$ & \\
Petani & $83(66.9 \%)$ & $16.67 \pm 7.7$ & \\
Lain-lain & $12(9.7 \%)$ & $14.17 \pm 6.7$ & \\
Penghasilan & $8(6.5 \%)$ & $13.5 \pm 6.92$ & \\
2 UMR & & & 0.467 \\
< UMR & $1(0.8 \%)$ & - & \\
\hline & $123(99.2 \%)$ & $15.54 \pm 7.5$ & \\
\hline & & & \\
\hline
\end{tabular}

Catatan : ${ }^{\mathrm{U}} \mathrm{Uji}$ Mann whitney atau Kruskal-Wallis dengan * $\mathrm{p}<0.05$ menujukan signifikan dan ${ }^{* *}$ p $<0.01$ menunjukan signifikan kuat 
Tabel 3. Perilaku Kesehatan Gigi Mulut dan DMF-T Lansia

\begin{tabular}{|c|c|c|c|}
\hline & \multirow{2}{*}{$\mathbf{N}(\%)$} & \multicolumn{2}{|c|}{ DMF-T } \\
\hline & & $($ Mean \pm SD) & $p^{\mathrm{a}}$ \\
\hline Jumlah Gigi tersisa & & & $0.007^{* *}$ \\
\hline$\geq 20$ gigi & $67(54 \%)$ & $13.6 \pm 7.4$ & \\
\hline$<20$ gigi & $57(46 \%)$ & $17.13 \pm 7.2$ & \\
\hline Rasa sakit 12 bulan terakhir & & & 0.324 \\
\hline $\mathrm{Ya}$ & $99(79,8)$ & $15.18 \pm 7.3$ & \\
\hline Tidak & $35(20,2)$ & $16.8 \pm 8.3$ & \\
\hline Pemakaian protesa & & & 0.053 \\
\hline $\mathrm{Ya}$ & $17(13.7 \%)$ & $18.76 \pm 7.35$ & \\
\hline Tidak & $107(86.3 \%)$ & $15 \pm 7.42$ & \\
\hline Penilain diri terhadap kesehatan gigi & & & $0.016^{*}$ \\
\hline Baik & $24(19,3 \%)$ & $19.13 \pm 8.53$ & \\
\hline Sedang & $66(53,2 \%)$ & $13.58 \pm 6.29$ & \\
\hline Buruk & $34(27,4 \%)$ & $16.71 \pm 7.9$ & \\
\hline Frekuensi Menyikat gigi & & & 0.118 \\
\hline Tidak Pernah & $4(3,2 \%)$ & $22.75 \pm 7.63$ & \\
\hline $2-6 \mathrm{x}$ seminggu & $3(2,4 \%)$ & $11.33 \pm 6.11$ & \\
\hline 1 kali sehari & $16(12,9 \%)$ & $13.81 \pm 7.3$ & \\
\hline$\geq 2$ kali sehari & $101(81,5 \%)$ & $15.61 \pm 7.45$ & \\
\hline Penggunaan sikat gigi & & & $0.026^{*}$ \\
\hline Tanpa sikat gigi & $2(1,6 \%)$ & $24 \pm 11.31$ & \\
\hline Sikat gigi & $45(36,3 \%)$ & $17.8 \pm 8.3$ & \\
\hline Sikat gigi dan alat lain & $77(62,1 \%)$ & $14 \pm 6.5$ & \\
\hline Penggunaan Pasta Gigi & & & $0.009^{* * *}$ \\
\hline Tidak Pakai Pasta gigi fluoride & $10(8 \%)$ & $21.9 \pm 7.7$ & \\
\hline Pakai pastag gigi fluoride & $114(92 \%)$ & $15 \pm 7.3$ & \\
\hline Frekuensi kunjungan terakhir kali ke dokter gigi & & & $0.044^{*}$ \\
\hline$<6$ bulan & $19(15,3 \%)$ & $13.53 \pm 8.0$ & \\
\hline $6-12$ bulan & $15(12,1 \%)$ & $18.33 \pm 5.4$ & \\
\hline$>1$ tahun & $31(25.1 \%)$ & $14.35 \pm 8.4$ & \\
\hline Tidak pernah & $59(47.6 \%)$ & $16.03 \pm 7.2$ & \\
\hline Alasan ke dokter gigi & & & 0.223 \\
\hline Sakit atau masalah dengan gigi mulut & $60(48,4 \%)$ & $14.78 \pm 7.7$ & \\
\hline Perawatan lanjutan & $2(1,6 \%)$ & $18.00 \pm 5.7$ & \\
\hline Perawatan rutin & $1(0,8 \%)$ & - & \\
\hline Tidak pernah & $61(49,2 \%)$ & $16.3 \pm 7.36$ & \\
\hline Frekuensi gangguan gigi dan mulut 12 bulan terakhir & & & 0.585 \\
\hline Tidak ada & $85(68,5 \%)$ & $15.15 \pm 6.76$ & \\
\hline Kadang-kadang & $35(28,2 \%)$ & $16.71 \pm 9.25$ & \\
\hline Sering & $4(3,2 \%)$ & $12.5 \pm 4.12$ & \\
\hline Frekuensi Makan manis & & & 0.216 \\
\hline Jarang & $79(63.7 \%)$ & $15.23 \pm 7.38$ & \\
\hline Kadang-kadang & $43(34,7 \%)$ & $16.35 \pm 7.76$ & \\
\hline Sering & $\begin{array}{l}43(34,7 \%) \\
2(1.6 \%)\end{array}$ & $8.5 \pm 0.7$ & \\
\hline Rutin Makan Buah & & & 0.413 \\
\hline Ya & $74(59,7 \%)$ & $15.15 \pm 7.46$ & \\
\hline Tidak & $50(40,3 \%)$ & $16.04 \pm 7.6$ & \\
\hline Rutin Makan Buah & & & 0.413 \\
\hline Ya & $74(59,7 \%)$ & $15.15 \pm 7.46$ & \\
\hline Tidak & $50(40,3 \%)$ & $16.04 \pm 7.6$ & \\
\hline Frekuensi Merokok & & & 0.119 \\
\hline $\mathrm{Ya}$ & $24(19,4 \%)$ & $13.5 \pm 6.67$ & \\
\hline Tidak & $100(80,6 \%)$ & $16 \pm 7.63$ & \\
\hline
\end{tabular}

Catatan : ${ }^{a} \mathrm{Uji}_{\mathrm{ji}}$ Mann whitney atau Kruskal-Wallis dengan ${ }^{*} \mathrm{p}<0.05$ menujukan signifikan dan $* * p<0.01$ menunjukan signifikan kuat 
diperoleh dari presentase F-T/DMF-T adalah $1.3 \%$ dan untuk RTI (Required Treatment Index) dari presentase D-T/DMF-T adalah $45.76 \%$. Hasil lebih jelas mengenai nilai DMFT dapat diihat pada tabel 1.

Uji deskriptif pada faktor sosiodemografi dan hasil uji bivariatnya dengan nilai DMF-T dapat dilihat pada tabel 2, sedangkan uji deskriptif dan bivariat antar perilaku kesehatan gigi mulut lansia dengan nilai DMF-T terdapat pada tabel 3. Hasil analisis yang menunjukan terdapat perbedaan signifikan rerata nilai DMF-T antar grup adalah berdasarkan usia, pendidikan terakhir, jumlah gigi yang tersisa, penilaian diri terhadap kesehatan gigi, penggunaan sikat dan pasta gigi serta frekuensi kunjungan terakhir kali ke dokter gigi.

\section{DISKUSI}

Menurut WHO, untuk menilai status kesehatan gigi dan mulut dalam hal ini karies gigi permanen digunakan nilai DMF-T (decay missing filled teeth). Nilai DMF-T menunjukkan jumlah karies pada seseorang atau sekelompok orang. Oleh karena itu, untuk menilai status karies pada masyarakat Desa Pagedangan Ilir, Kecamatan Kronjo, Kabupaten Tangerang, Priovinsi Banten, peneliti menggunakan Borang Pemeriksaan Kesehatan Gigi dan Mulut Dewasa versi WHO (Annex 1). Untuk menilai perilaku masyarakat, digunakan kuesioner WHO Annex 7 yang terdiri dari 16 pertanyaan yang meliputi pengetahuan, sikap dan tindakan kesehatan gigi dan mulut. ${ }^{6}$

Hasil penelitian menunjukkan prevalensi karies di Desa Pegadangan Ilir sangat tinggi yaitu sebesar $95.16 \%$. Subjek penelitian yang tidak memiliki karies dikarenakan semua gigi telang hilang (missing) bukan karena benarbenar sehat atau free caries. Status karies gigi subjek penelitian berdasarkan rerata nilai DMF-T pada masyarakat Desa Pagedangan Ilir masuk pada kategori sangat tinggi yaitu 15,52, dengan rata-rata $\mathrm{D}-\mathrm{T}$ sebesar 7,1 dan $\mathrm{M}-\mathrm{T}$ sebesar 8,21 yang menunjukkan bahwa setiap lansia rata-rata memiliki 7 gigi yang berlubang dan 8 gigi yang hilang atau harus dicabut. Perhitungan PTI yang artinya berapa persen karies gigi yang telah mendapatkan perawatan dengan penambalan ternyata sangat rendah hanya $1.3 \%$ saja dari kerusakannya $(\mathrm{RTI}=$ $45.76 \%)$.

Hasil uji statistik menunjukkan bahwa terdapat perbedaan yang bermakna antar kelompok usia $(p=0.001)$, yaitu usia 56-65 tahun memiliki rerata nilai DMFT lebih tinggi dibandingkan kelompok usia dibawahnya. Hal ini dikarenakan semakin tinggi usia seseorang maka semakin lama ia terpapar oleh faktor penyebab karies gigi sehingga memiliki kerusakan yang lebih parah. Sebaliknya, pada penelitian ini hasil menunjukkan tidak terdapat perbedaan yang bermakna antar kelompok gender dengan nilai DMF-T meskipun nilai rata-rata DMFT Perempuan lebih tinggi

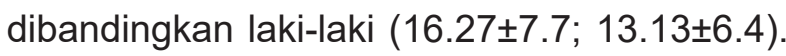
Menurut Burt, 2005, pertumbuhan gigi pada anak perempuan lebih awal daripada anak laki-laki, sehingga masa terpapar dalam mulut lebih lama. Antara anak laki-laki dan perempuan pada umur kronologi yang sama, secara statistik prevalensi kariesnya berbeda bermakna, pada anak perempuan prevalensi kariesnya lebih tinggi daripada anak laki-laki. ${ }^{7}$

Sedangkan, untuk pendidikan terakhir pada penelitian ini menunjukkan terdapat perbedaan yang bermakna $(p=0.014)$ dengan nilai rerata DMF-T kelompok yang tidak sekolah lebih tinggi dibandingkan dengan pendidikan SD dan SMP, meskipun begitu ternyata nilai rerata DMF-T Lansia lulusan SMAlebih tinggi dibandingkan 
yang tidak sekolah. Menurut Tirthankar, pendidikan adalah faktor sosial ekonomi yang mempengaruhi status kesehatan. Seseorang yang memiliki tingkat pendidikan yang tinggi akan memiliki pengetahuan dan sikap yang baik tentang kesehatan sehingga akan mempengaruhi perilakunya untuk hidup sehat. ${ }^{8}$

Beberapa penelitian sebelumnya melaporkan adanya hubungan bermakna antara pendidikan dan karies gigi. ${ }^{9,10}$ Menurut penelitian Wan, dkk tahun 2010 di Malaysia yang menyebutkan bahwa tingkat pendidikan merupakan salah satu indikator yang digunakan dalam mengukur status sosial ekonomi yang menunjukkan hubungan yang signifikan dengan kejadian karies. ${ }^{11}$ Pada penelitian ini hasilnya terdapat perbedaan yang bermakna antara pengetahuan mengenai jumlah gigi yang dimiliki saat ini dengan rerata nilai DMF-T yaitu subyek yang merasa memiliki gigi lebih dari 20 nilai DMF-T nya lebih rendah dibandingkan subyek yang merasa gginya kurang dari 20 $(p=0.007 ; 13.6 \pm 7.4 ; 17.13 \pm 7.2)$.

Terdapat hasil yang signifikan antara penggunaan penggunaan pasta gigi dengan DMF-T. Hasil penelitian ini didukung oleh penelitian sebelumnya yang dilaporkan Linardi tahun 2014 yang juga menemukan hubungan bermakna antara penggunaan pasta gigi berfluoride dengan prevalensi karies. ${ }^{12}$ Fluor dapat mengurangi plak pada gigi, bakteri, dan juga dapat membantu proses remineralisasi email yang terjadi pada $\mathrm{pH} 7$, sedangkan pada $\mathrm{pH} 4.3$ terjadi demineralisasi email. ${ }^{13}$

Hasil uji statistik menunjukkan bahwa tidak terdapat hubungan yang bermakna atau signifikan antara makan buah dan makan manis dengan DMF-T. Hasil penelitian ini tidak didukung oleh literatur dan penelitian-penelitian yang telah dilakukan sebelumnya. ${ }^{14} \mathrm{Hal}$ ini mungkin merupakan akibat dari kelemahan metode penelitian dengan wawancara yang sangat subjektif, sehingga risiko bias dapat terjadi.

Keterbatasan dalam penelitian ini adalah jumlah sampel lansia yang masih rendah karena belum dapat mewakili semua desa di kecamatan Kronjo sehingga beberapa faktor resiko dari perilaku kesehatan gigi mulut belum menunjukan hasil yang bermakna secara signifika serta jumlah examiner 4 orang menjadi risiko bias, meskipun examiner sudah dikalibrasi dan hasilnya adalah substantial agreement (persetujuan baik).

\section{DAFTAR PUSTAKA}

1. Sekarwiri E. Hubungan antara fungsi keluarga dan kualitas hidup lansia. Jakarta : PSI UI 2008 ;9-16

2. Ratmini. NK, Arifin.Hubungan kesehatan Mulut dengan kesehatan Mulut lansia. Jurnal Perawat Gigi, Universitas Gajah Mada. 2011 ; Vol.2 (2) pp :140- 145.

3. Pertiwi ASP, Sasmita IS, Suptarini R. Gambaran pola karies gigi permanen ditinjau dari dental neglect siswa kelas 5-6 SDN Cikudayasa kec. Cileunyi Kabupaten Bandung. Bandung: Unpad, 2007; p.4.

4. Sihite, John H. Hubungan tingkat sosial ekonomi orang tua dengan status bebas karies pada anak usia 7-11 tahun. Medan: Universitas Sumatera Utara [Online]. 2012 [cited: April 2013]. Available from: URL: http://repository.usu.ac.id/handle/12345678 9/33762

5. Balitbang Kemenkes RI. Riset Kesehatan Dasar; RISKESDAS. Jakarta: Balitbang Kemenkes RI, 2013.

6. Oral Health Surveys Basic Methods 5th Edition. World Health Organization 2013.

7. Jovina, Tince Arniati.. Pengaruh Kebiasaan Menyikat Gigi Terhadap Status Pengalaman Karies Riskesdas 2007. Jakarta: Fakultas Kesehatan Masyarakat Program Studi IImu Kesehatan Masyarakat Universitas Indonesia, 2010.

8. Ramadhan, A. Hubungan Tingkat Pengetahuan Kesehatan Gigi dan Mulut Terhadap Angka Karies Gigi di SMPN 1 Marabahan. Dentino Jurnal Kedokteran Gigi. 2016: Vol I. No 2

9. Wulandari, Rahmi. Hubungan Tingkat Pendidikan Dan Status Ekonomi Dengan Kedalaman Karies Gigi pada Pasien Di Puskesmas Turi Kabupaten Sleman. Jurnal Kedokteran Gigi. 2005 1-5.

10. Nurfitasari dan Medawati. Hubungan Status Sosial Ekonomi dan Tingkat Pendidikan Orang Tua Terhadap Tingkat Keparahan Karies pada Anak 
Retardasi Mental (Kajian Pada SLB-C Dharma Rena Ring Putra II Yogyakarta). 2012

11. Ws, wan salina, Nizam A, Naing L. The Association of Birth Order And Sociodemographic Factors With Caries Experience Among Adolescents In Tumpat. Archieves of Orofacial Sciences. 2007; p. 45-50.

12. Linardi AN Perbedaan $\mathrm{PH}$ saliva antara pengguna pasta gigi yang mengandung baking soda dan pengguna pasta gigi yang mengandung fluor (skripsi). Makassar, Universitas Hasanuddin. 2014.

13. Maldupa I, Anda B, Inga R, Anna M. Evidence base toothpaste classification, according to certain characteristics of their chemical compotition.Baltic Dental and Maxillofacial Journal. 2012; 14(1), 13, 16-9

14. Jamel $H$, Sheiham A, Watt R, Cowell C. Sweet preference, consumption of sweet tea and dental caries; studies in urban and rural Iraqi populations. Int Dent J 1997. 47(4):213-217. 